\title{
Conducta ante la Gestante Rh Negativa
}

\author{
Por el Doctor Ernesto Plata Rueda \\ Jefe de Clínica de Sala-Cuna del Instituto Materno-Infantil.
}

El presente trabajo es el resultado de la experiencia adquirida en la Clínica David Restrepo de Bogotá, en el manejo de -1 gestantes Rh negativas, de algunos casos hospitalarios en el Instituto de Proteccion Materna e Infantil de Bogotá y de 7 Eritroblastosis fetales tratadas personalmente en la clientela civil.

I os conceptos fundamentales sobre Rh y Eritroblastosis fetal están hov suficientemente difundidos entre obstetras y pediatras. por lo cual me limitaré a recordar solamente los puntos fundamentales con el fin de hacer más clara la exposición sobre la conducta a seguir ante la gestante Rh negativa.

El descubrimiento del factor $\mathrm{Rh}$ se originó en una experiencia animal muy interesante: la invección de glóbulos rojos del mono Rhesus al conejo, determina por parte de éste la producción de una sustancia que aglutina al $85 \%$ de las sangres de la población blanca. Esto quiere decir que el $85 \%$ de la población blanca tiene en su sangre, al igual que el mono Rhesus una sustancia aglutinógena, mientras que un $15 \%$ carecen de ella. A los primeros se les denominó $\mathrm{Rh}$ positivos $y$ a los segundos Rh negativos.

La primera aplicación clínica de este descubrimiento fue encontrar una ex plicación para los casos de hemolisis que se presentaban en algunos sujetos a quienes se les practicaba una segunda transfusion con sangre debidamente clasificada: estos individuos eran $\mathrm{Rh}$ negativos $\mathrm{y}$ al recibir una transfusión de sangre $\mathrm{Rh}$ positiva elaboraban anticuerpos anti Rh capaces de hemolizar los glóbulos rojos de una segunda transfusión.

La segunda aplicación clínica del descubrimento del factor $\mathrm{Rh}$ fue que la gran mayoría de las madres que perdían sus hijos recién nacidos con la llamada Anemia Hemolítica Congénita, eran Rh negativas mientras sus esposos eran Rh positivos.

Sin entrar en otros detalles veamos qué condiciones se requieren para que un matrimonio colocado ante esta situación dé lugar a hijos Eritroblastósiços. 
10-Que haya paso de glóbulos rojos del feto a la madre para lo cual es evidente que se necesitan ciertos defectos en los vasos o en la implantación placentaria.

20-Que la madre sea capaz de formar anticuerpos anti $\mathrm{Rh}$ : se ha calculado que sólo una de cada 25 madres Rh negativas tiene este poder antigénico.

30-Que los anticuerpos ya formados por la madre pasen al feto a través de la placenta, para lo cual deben poseer una molécula muy pequeña.

$4^{\circ}$-Que la madre haya desarrollado de antemano anticuerpos anti Rh, bien sea por embarazos y partos anteriores, bien por raspados de abortos Rh positivos que siembran glóbulos rojos en la pared uterina o por transfusiones imprudentes de sangre Rh positiva en cualquier época de su vida.

Resulta de ésto una frecuencia realmente escasa de la enfermedad, como se desprende de nuestras propias estadisticas: en la Clínica David Restrepo la incidencia de madres $R h$ negativas no es del $15 \%$ como se anota en la literatura para la población blanca, sino del $6,3 \%$, cifra análoga a la que se da para los negros ${ }^{1}$ y asiáticos ${ }^{2}$. Recordemos que entre los filipinos e indonesios no se encuentra población $R$ h negativa ${ }^{3}$. Tal vez fuera éste un pequeño argumento en favor del origen oriental de nuestras razas indigenas.

Sobre 708 partos, de los cuales 39 han sido en madres Rh negativas sólo se ha presentado un mortinato imputable a Eritroblastosis y una ictericia hemolítica benigna atribuíble a la misma causa. Esto da para la Eritroblastosis en nuestro medio una incidencia de 1 por cada 500 partos, es decir la mitad de la incidencia citada por los autores norteamericanos. Ello puede deberse en partc a que el $53 \%$ de estas gestantes Rh negativas fueron primi y segundigestantes en quienes no era de esperar ningún problema a este respecto. Sin embargo, cabe anotar que el $29 \%$ de esas pacientes desarrollaron anticuerpos con titulos positivos desde 1 por 2 hasta 1 por 32 .

Veamos ahora algunos detalles sobre el problema de los anticuerpos bloqueadores, que son de conocimiento menos difundido. Cuando va la investigación estaba muy avanzada, quedaba sin solucion un problema bastante común cual era el de que las madres Rh negativas de niños portadores de las formas más graves de Eritroblastosis, aparentaban no tener anticuerpos anti $\mathrm{Rh}$ en su sangre: es decir, que su suero no era capaz de aglutinar los glóbulos rojos Rh positivos $\mathrm{O}$, con los que se le ponian en contacto. La explicacion de este fenómeno está en que, en algunas madres los anticuerpos anti Rh pueden ser univalentes y no bivalentes como es lo común. Al poner anticuerpos bivalentes anti Rh en contacto con glóbulos rojos hh positivos $O$, es natural que éstos se aglutinen encadenados mutuamente por los anticuerpos; pero cuando el suero contiene sólo anticuerpos monovalentes, tal encadenación no es posible porque los glóbulos rojos se rodean de una capa de anticuerpos que carecen de valen. cia en su periferia.

La importancia práctica, que ésto tiene es enorme, en primer lugar porque en el curso de un embarazo, una madre puede estar pasando como incapaz de formar anticuerpos, cuando en realidad los está formando del tipo monovalente, más peli- 
groso porque por ser de molécula pequeña pasan fácilmente la placenta en un período precoz del embarazo y pueden dar hasta abortos ${ }^{4}$. En segundo lugar un niño hijo de una gestante Rh negativa la cual ha formado anticuerpos monovalentes, puede aparentar ser Rh negativa, cuando en realidad lo que ocurre es que sus glóbulos están bloqueados por el anticuerpo monovalente y no se aglutinan en la prueba común para el Rh. Afortunadamente disponemos hoy ya en nuestro medio de técnicas sencillas para revelar también estos anticuerpos bloqueadores.

Con estos fundamentos vamos a ver sumariamente cuál es la conducta ceintifica del obstetra ante la gestante Rh negativa.

\section{Durante el Embarazo:}

10-A toda gestante debe ordenársele la investigación del tipo $\mathrm{Rh}$ a que pertenece, así como su grupo sanguíneo. La reacción la ejecutará el laboratorio poniendo en contacto sus glóbulos rojos con los antígenos Rho y Rhl, que abarcan casi toda la potitividad existente.

20.-Si resulta $\mathrm{Rh}$ negativa debe practicarse el $\mathrm{Rh}$ del esposo con los mismos antigenos.

$3^{\circ}-$ Si el esposo pernece al grupo Rh positivo con cualquiera de los antígenos, se procederá a partir del $5^{\circ}$ mes a la investigación de los anticuerpos en el suero materno. Se ordenará primeramente una investigación cualitativa para averiguar tanto la presencia de los anticuerpos bivalentes como la de los monovalentes. La reacción de los anticuerpos bivalentes se denomina reacción de aglutinación "y consiste en poner suero de la madre en contacto con globulos rojos Rh positivos $\mathrm{O}$ : si los aglutina la reacción se reporta como positiva, es decir que existen anticuerpos bivalentes en el suero materno. La investigación de los anticuerpos monovalentes o bloqueadores pueden hacerse de 3 maneras: la primera se denomina prueba de bloqueo" se ponen en contacto glóbulos rojos Rh positivos $\mathrm{O}$ más suero de la paciente más antígeno $\mathrm{Rh}$; si no hay anticuerpos de bloqueo, el antígeno Rh produce una intensa aglutinación; pero si los glóbulos rojos están rodeados de anticuerpos bloqueadores, la aglutinación no se produce pese a la presencia del antígeno Rh. La segunda se denomina praeba de la conglutinación "y consiste en poner en contacto glóbulos rojos Rh positivos $\mathrm{O}$, suero de la paciente y albúmina bovina; esta última hace que, si hay anticuerpos bloqueadores la aglutinación se produzca. La tercera, que es la más sensible se denomina prueba de la antiglobulina '. Poniendo en contacto glóbulos rojos Rh positivos $\mathrm{O}$ con suero de la paciente y suero anti-humano de conejo, la aglutinacion se produce si existen anticuerpos bloqueadores.

$4^{\circ}-$ Cuando cualquiera de estas pruebas diere resultado positivo, debe procederse mes por mes a ordenar la titulación de los anticuerpos completos e incompletos, para lo cual el laboratorio ejecuta las pruebas descritas utilizando diluciones crecientes del suero de la madre. 


\section{Conducta Obstetrica:}

10-En la primigestante sin antecedentes de transfusión incompatible, no existe ninguna preocupación, pues los títulos no serán nunca tan altos como para perjudicar al feto. Los controles podrá ser menos frecuentes y muchas veces bastará con una titulación al noveno mes para que sirva de orientación en futuros embarazos. En nuestra estadística sólo un $5 \%$ de las pacientes se sensibilizaron en el primer embarazo.

$2^{\circ}$ - En la secundigestante se vigilarán minuciosamente los títulos y si sobrepasan el 1 por 32 se debe tener listo en el momento del parto, todo el equipo de investigacion y tratamiento para la Eritroblastosis. La secundigestante que fue controlada en su primer embarazo y no hizo aglutininas, puede considerarse desde este punto de vista de la conducta como una primigestante y asi sucesi vamente en futuros embarazos.

30-En la multigestante sin antecedentes de abortos, mortinatos ni muer tes post-natales sospechosas de Eritroblastosis, la conducta será igual que para la secundigestante.

4?-En la multigestante con antecedentes sospechosos, o en lo primigestante sensibilizada por transfusión se vigilarán las aglutininas cada 15 dia a partir del séptimo mes y con títulos superiores al 1 por 16 en anticuerpos bloqueadoes, esta indicada la inducción de parto prematuro, a los $81 / 2$ meses" para disminuir el tiempo de sensibilización fetal que parece hacerse maciva en las ultimas semanas y durante el parto. Se tendrán disponibles todos los elementos para el tratamiento de la Eritroblastosis. Esta ha sido la conducta hasta ahora seguida entre nosotros y corresponde a los casos de este trabajo. 'Sin embargo existe hor una marcada tendencia a dejar hasta el término estos embarazos, para no sumar al problema de la Eritroblastosis, el de la prematurez. Es sabido que las formas mas graves de Eritroblastosis se observan de preferencia en prematuros".

$5 \%$ - En la multigestante con antecedentes francos de fetos muertos in utero está indicada la práctica del parto prematuro entre el 8 y el $81 / 2$ mes. en un intento de esquivar la muerte intrauterina del feto, teniendo a mano todos los elementos para el tratamiento inmediato.

$6{ }^{\circ}$ - La cesarea con raquianestesia ha sido hasta hoy el procedimiento elegi. gido para la induccion de parto prematuro "." por considerar que las contracciones uterinas "exprimen" por así decirlo, aglutininas en la sangre fetal.

\section{Conducta en el Parto:}

19-A todo recién nacido hijo de gestante $\mathrm{Rh}$ negativa debe extraérsele sangre del cordón y ordenar los siguientes exámenes: Rh, prueba de Coombs, cuadro hematico. anticuerpos completos e incompletos y grupo sanguíneo. Se tomará también sangre del talón para grupo sanguíneo, la cual tiene un recuento globular un poco inferior a la del cordón y se presta mejor como punto de partida para los controles que luégo se hagan sobre sangre obtenida en esta for- 
ma. La prueba de Coombs es una prueba de anyiglobulina que permite desen mascarar los falsos Rh negativos por bloqueo.

$2^{\circ}$ - Si el niño es realmente $\mathrm{Rh}$ negativo la investigación puede terminar pues no hay lugar a Eritroblaștosis.

$3^{\circ}$ - Si el niño es $R$ h positivo la conducta a seguir varía según los antecedentes obstétricos de la madre y el título a que llegaren las aglutinas.

Así: 10-Los hijos de primigestantes o de multigestantes sin antecedentes sospechosos, merecen sólo un control clínico. Lo mismo puede decirse de aquellos a quienes no se encuentre ninguna aglutinina en la sangre del cordón.

$2^{\circ}$ - L Los hijos sanos de multigestantes con antecedentes sospechosos o sin ellos pero con elevar'as aglutininas deben someterse a control clínico riguroso y a] cuadro hemático cada 24 horas.

30-Para el parto de la multigestante con antecedentes francos, deberá disponerse previamente de todos los elementos para practicar una exsanguino transfusión en el momento del parto, tan pronto como se conozca allí que el niño pertenece al grupo Rh positivo y existan aglutininas en la sangre del cordón.

\section{Tratamiento del Niño:}

$1^{\circ}$ - Se tratarán con exsanguino transfusión además de los acabados de citar, los casos de ictericia intensa sin anemia, los de edema generalizado con o sin anemia, los hijos de madres con título alto de anticuerpos bloqueadores por el peligro de taponamientos intravasculares hepaticos y cerebrales aún en ausencia de anemia; los niños con manifestaciones neurologicas de la Eritroblastosis (kernicterus) y las anemias graves de menos de tres millones de glóbulos rojos por $\mathrm{mm}^{3}$. La exsanguino transfusićn en la vena cara por intermedio de la vena umbilical y valiéndose de una cánula de poliethileno $\mathrm{N}^{0} 160$, es fácil a condición de heparinizar todo el material. Por esta via puede hacerse la transfusión hasta 12 horas después del parto por lo cual conviene que el obstetra cuando calcule que va a necesitarse tal procedimiento, deje un poco más largo el muñón umbilical. Para que la exsanguino transfusion resulte eficaz debe hacerse un recambio de sangre de 500 c.c. (sangre Rh negativa).

2:-Las pequenas transfusiones repetidas de sangre Rh negativa sólo están indicadas en las formas simples de ictericia hemolítica cuando ia cifra de glóbulos rojos no es inferior a 3.000 .000 por $\mathrm{mm}^{3}$. La sangre $\mathrm{Rh}$ positiva nunca debe usarse pues se hemoliza. Como último recurso en ausencia de un dador Rh negativo compatible puede usarse glóbulos rojos lavados, de la misma madrc

\section{Profilaxis.}

En \&l tratamiento profiláctico de la gestante sensibilizada o sensibilizable se ha ensayado el uso de una sustancia denominada Hapteno $\mathrm{Rh}$, extraída de glóbulos rojos y carente de poder antigénico, que se apoderaría de los anticuerpos anti $\mathrm{Rh}$ in vivo; no ha llegado hasta nosotros y los resultados obtenidos en el ex- 
terior no han sido alentadores. La vitamina E y la hormona del cuerpo lúteo a favorecer la implantación y la integridad placentaria, parece que tienen valor, aunque las publicaciones al respecto son contradictorias. Personalmente conozco a!gunos casos aparentemente muy satisfactorios, pero apenas tenemos en camino una investigación que tenga valor estadístico. Ambas son inocuas y se justifica ahora su uso; $100 \mathrm{mlg}$. de vitamina $\mathrm{E}$ por día o $10 \mathrm{mlg}$. vía oral por día de progesterona, a partir del tercer mes.

\section{B I B L IOGRA F I A}

1.-Wiener, A. S., Belkin, R. B. y Sonn, E. B.: "distribution of the Al - A2 - B-O., $\mathrm{M}-\mathrm{N}$ and Rh Blood factors among Negroes in New York City". Am. J. Phis. Anthropol. 2,187 (1944).

2.-Wiener, Sonn y Belkin: "J. Inmunol". 50, 341 (1945).

3.- Simons, R. T.: "Medic. Jour. Austral", 2, 325 (1945).

4.-Wiener A. S.: "A new Test" (Blocking Test) for Rh Sensitization, "Proc. Soc., Exper. Biol, \& Med.", 56, 173 (1944).

Race R. R.: An "Incomplete" Antibody in Human Serum, Nature, 153, 771 (1944).

Diamond, L. K. y Abelson, N. M.: Importance of Rh Inhibitor Substance in Anti Rh Serum, "J. Clin. Investigation", 24, 122 (1945).

5. -Wiener A. S.: Recent Developments in the Knowledge or the Rh- $\mathrm{Hr}$ Blood Types; Tests for Rh Sensitization, Am. J. Clin. Path. 16: 477 (aug). 1946.

6.-Wiener, A. S.: Conglutination Test for Rh Sensitization, "J. Lab. \& Clin. Med.", 30, 662 (1945).

7. Coombs, R. R. A.: Mourant, A. E., and Race, R. R.: A New Test for the Detection of Weak and "Incomplete" Rh Agglutinins, Brit. J. Exper. Path., 26: 255, 1945.

Wiener, A. S. and Hurst, J. G.: A new Sensitive Test (Direct Test) for Rh Blocking Antibodies. Exper. Med. \& Surg. 5: 285 (may.-aug.), 1947.

8.-Klebanow and Mayr: Geburtshilfe und Frauenheilkunde, Stuttgart 9: 873944 (dec.) 1949, p. 931

9.Diamond, L. K., Mitchell-Nelson: Text Book of Pediatrics. Fifth Edition p.1.119.

10.-Hocks H.: Critical Evaluation of Premature Cesarean Section in Suspected Fetal Erytroblastosis. "Geburtshilfe und Frauenheilkunde", Stuttgart 9: 873; 944 (dec.) 1949, p. 936. 